11. Wolfe R J Tarnished idol: William Thomas Green Morton and the introduction of surgical anesthesia. pp 129-130. San Anselmo, CA, USA: Norman Publishing, 2001.

12. Aguilar H F. 'La Odontología'. Vol III. pp 413-415 Madrid: Facultad Odontologia, Universidad Complutense, 1894.

13. Long $C W$. An account of the first use of sulphuric ether by inhalation as an anaesthetic in surgical operations. South Med Surg J 1849; 5: 705-713.

DOI: 10.1038/sj.bdj.2012.526

\section{ASININE SYSTEM}

Sir, I write further to your editorial (Does $D$ put the Dilemma in CPD?; BDJ 2012; 212: 461). In my opinion the $B D J$ should be the flagship journal for the profession in the UK. However, this position is seriously undermined by the absurdities of the verifiable CPD available in each issue. With revalidation on the horizon the $B D J$ should be leading the profession by providing top quality CPD of true educational value, with a requirement to achieve a minimum of 75\% correct answers to well-crafted multiple choice questions (MCQs) to qualify for verifiable CPD hours.

Without even opening the plastic wrapper around the journals, it is almost possible to fulfil one's annual professional obligation to the General Dental Council (GDC). A further issue is the anodyne nature of the MCQs, with virtually no educational value. To illustrate this I undertook the CPD in every issue in 2011 with the aim of achieving the lowest possible score of correct answers to the online MCQs. Via a mixture of intentionally answering incorrectly, guesswork, and often not reading the papers, I scored 13 correct answers out of a possible maximum of 192.

I will be very happy to provide a copy of my record for the end of the year which shows zero correct answers over seven issues. As everyone in the profession is aware, these results did not stop me being granted 48 hours verifiable CPD for 2011 and my certificate states these hours were awarded for 'Reading clinical articles and submitting answers to multiple choice questions' - of course no reference is made to the veracity of these answers. Whilst I choose to ignore these hours in my annual GDC submission, I could have elected to claim all of them and almost reach the total annual requirement of 50 hours $\mathrm{CPD}$.
Currently an appalling example is being set, especially to recent graduates and colleagues arriving from overseas, in that the $B D J$ places a very low emphasis on the value of the CPD process. In my view the current asinine system should have a complete overhaul to provide valid verifiable CPD for the profession.

S. Wilson

By email

Editor-in-Chief's note: Have your say. If you think Dr Wilson's view is correct or if you think otherwise, our online survey on the future of CPD in the BDJ is open until 31 July 2012 at www.bdjeastmancpd.com. Please give us your views. DOI: 10.1038/sj.bdj.2012.527

\section{DIAMANTÉ RADIOPACITIES}

Sir, a 32-year-old female presented at the local oral surgery department following a referral by her GDP for extraction of her lower left wisdom tooth. The patient complained of recent recurrent infections of the wisdom tooth for which her dentist gave her antibiotics. The medical history was unremarkable, and on examination a lower left partially erupted wisdom tooth was mesially impacting the adjacent molar tooth. A dental panoramic tomograph (DPT) was requested for assessment of the wisdom tooth (Fig. 1).

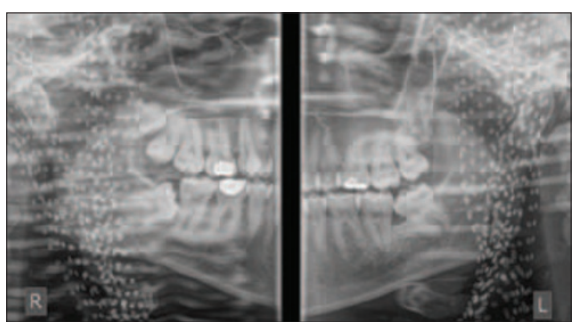

Fig. 1 DPT showing an unusual artefactual pattern

This radiograph is surprisingly unusual. In terms of the dentoalveolar anatomy, everything is ordinary apart from the supernumerary in the upper right quadrant. Multiple 2-3 $\mathrm{mm}$ welldefined circular radiopacities can be seen scattered bilaterally on the outer margins of the DPT. Meeting the patient again explained this anomaly. The patient was a Muslim woman wearing a headscarf with what seemed to be diamantés decorating it. This caused the artefacts. Although far from ideal, the radiograph was still diagnostically acceptable for the removal of the lower left wisdom tooth, however, if the lower right wisdom tooth were being assessed for extraction, this image would have been unacceptable as the radiopacities obstruct the view of the right inferior dental canal.

Being a Muslim myself, I completely understand the significance of a headscarf for a Muslim woman, but given that some hijabs can evidently distort a radiographic image, is it feasible to ask for the headscarf to be removed solely for the purposes of an extra-oral radiograph? After all, ear, nose and tongue piercings are all removed, as are spectacles and dentures. Otherwise, should we suggest to headscarf wearers that they ensure that scarves do not contain metallic decorations that can cause such artefacts? An interesting point, I think, to consider.

A. Maqbool, London DOI: 10.1038/sj.bdj.2012.528

\section{VOLUNTEER IN ECUADOR}

Sir, I wondered if you could post this vacancy among your members.

My name is Josephine Hook and I am from Edinburgh. I work for the charity Cenit in Quito, Ecuador, http://www. cenitecuador.org.

We are desperately short of dentists in our impoverished communities in the South of Quito. Cenit works mainly with working children and their families in the market areas. These children even at the age of four have very poor teeth. The school has 140 children and works with 250 families. There is one appointment twice a week for two children with a local dentist. We currently have a US student, who leaves in May, who has helped greatly in organising appointments with the dental students at a university nearby but medical and dental help is required urgently. This university will break up in July and August and that help will end. I wondered if any of your dental students, dentists or retired dentists would be interested in helping in Quito? If anyone speaks Spanish it would be most useful.

Thank you. DOI: 10.1038/sj.bdj.2012.529 